\title{
Molecular Structure of Metal Complexes of Certain Benzimidazole Derivatives
}

\author{
M N Manjunatha* \\ Department of Chemistry, M S Ramiah Institute of Technology, India
}

Submission: September 24, 2018 Published: September 28, 2018

"Corresponding author: M N Manjunatha, Department of Chemistry, M S Ramiah Institute of Technology, Bangalore-560 054, India, Email: mnmanjunathmsrit@gmail.com

Keywords: Molecular structure of bis [2-(4-methylsulfanylphenyl)-1H-benzimidazole] dibromidocadmium (II) ethanol (1) and 2-(p-thiomethylphenyl)benzimidazole tetrabromidocadmate (II) ethanol (2)

\section{Introduction}

Transition metal complexes containing imidazole and their derivatives have been shown to possess pharmacological activity [1,2] and have been used as antitumor and antimicrobial agents. Nitrogen heterocycles in general, and benzimidazole and their derivatives in particular, have been investigated for their antitumor, antibacterial, anti fungicidal, anticarcinogenic, anti-tubercular, anti-allergic and poliovirus inhibitor properties. Benzimidazole has a planar ring structure and is mainly used as an anticancer drug $[3,4]$. Nitrogen heterocycles are an interesting class of chelating agents and are capable of coordinating to one or more metal ions and thus forming mononuclear as well as polynuclear metal complexes. They find applications in analytical chemistry and also serve as biochemical models. Some of the first-row transition metal complexes of N-heterocycles containing benzimidazole moiety exhibit antifungal and antiviral activities $[5,6]$. Metal complexes containing N-heterocycles are also known to be good catalysts for hydrogenation, hydroformylation, transfer hydrogenation and related reactions involving organic substrates [7].

\section{Single Crystal X-ray Analysis and Refinement}

Single crystal X-ray diffraction data for the compounds $\mathbf{1}$ and 2 were collected on a Bruker Smart CCD Area Detector System [8], using MoK $\alpha(0.71073 \AA$ ) radiation for the crystal. Intensity data was collected up to a max of $26.81^{\circ}$ for the compound in the $w-\phi$ scan mode. The data was reduced using SAINTPLUS [8].

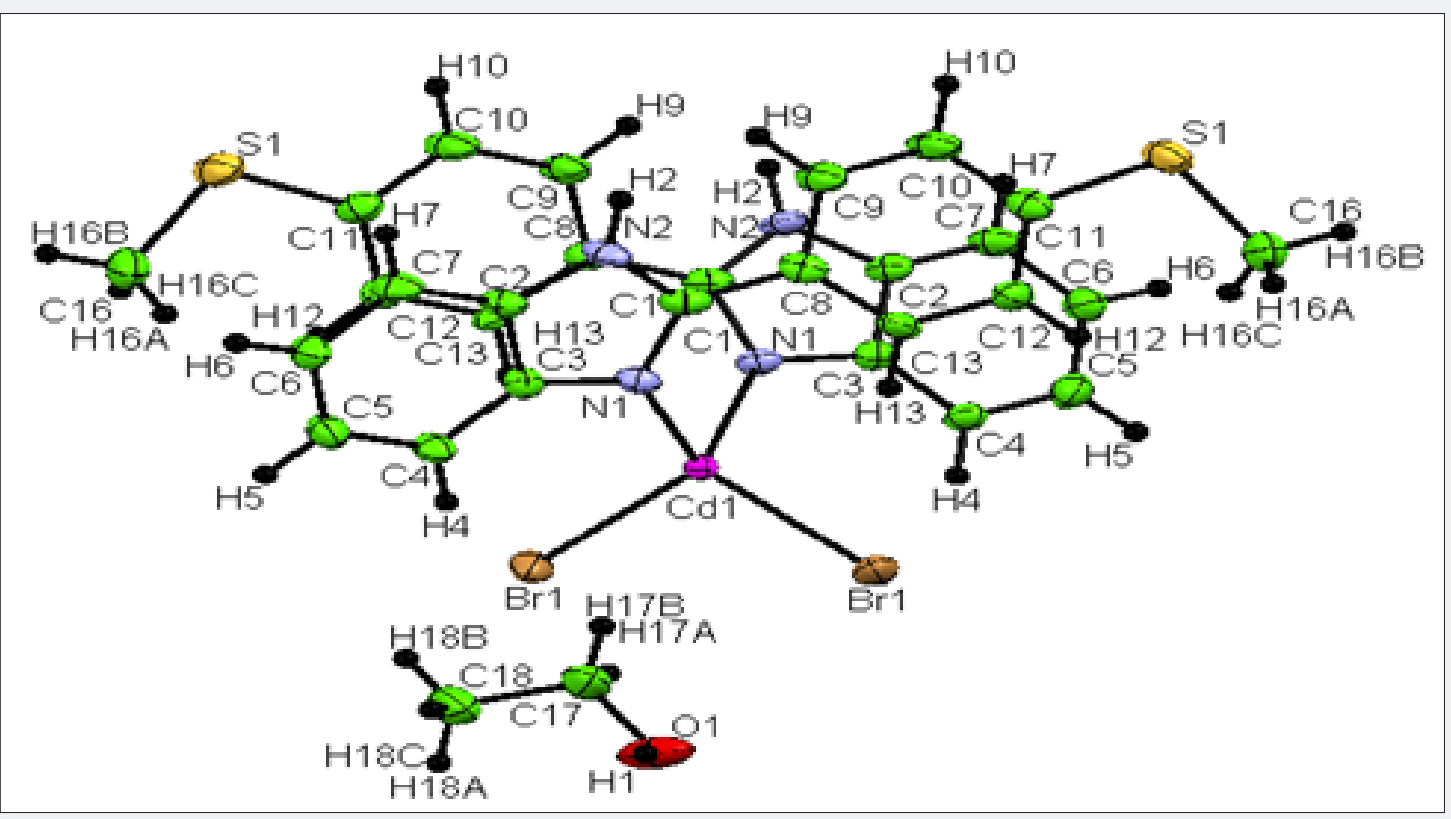

Figure 1: ORTEP diagram of compound 1 , showing $50 \%$ probability displacement ellipsoids and the atom-numbering scheme. 


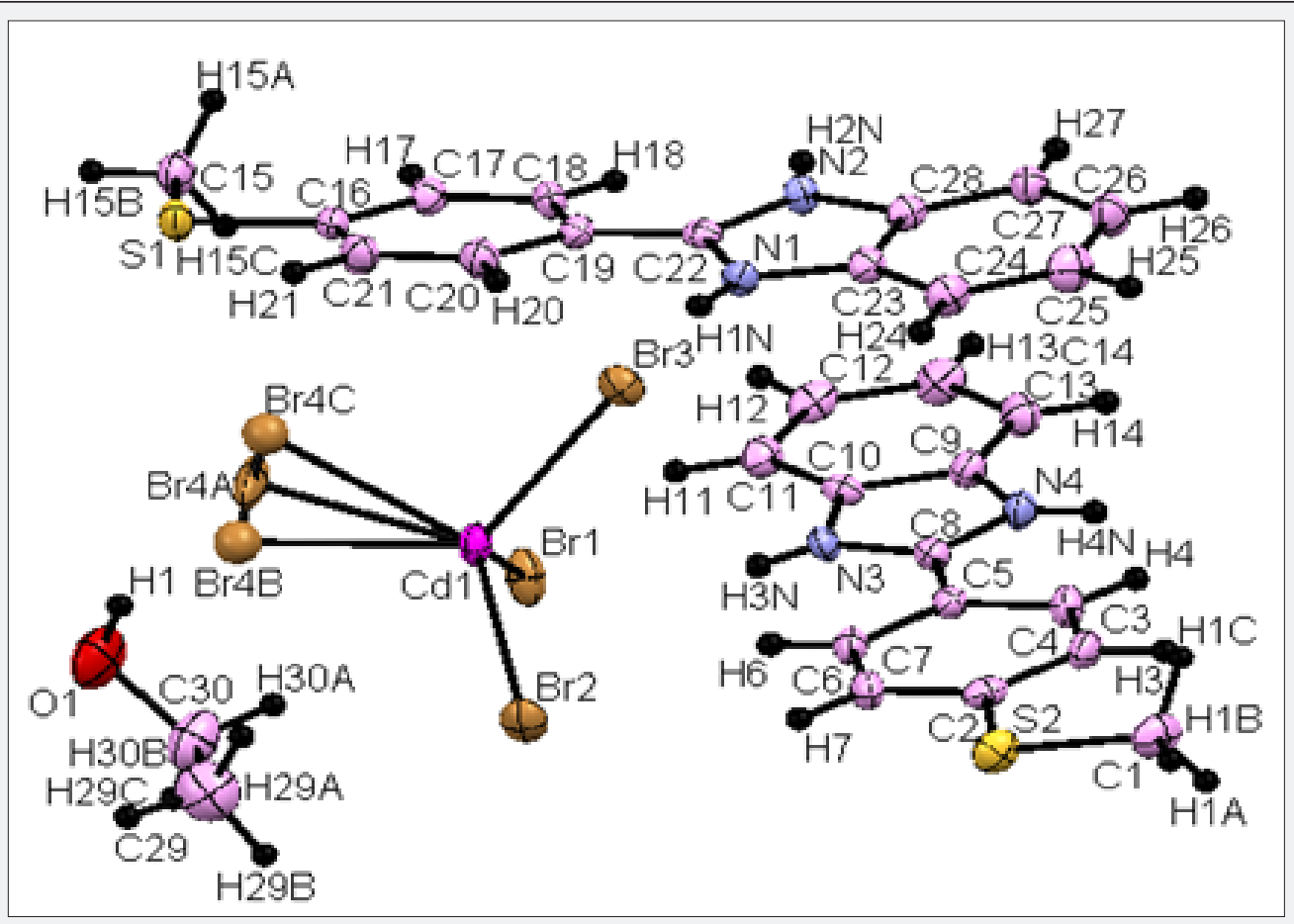

Figure 2: ORTEP diagram of compound 2 , showing $50 \%$ probability displacement ellipsoids and the atom-numbering scheme.

Compound 1: A total of 7272 reflections were collected, resulting in 7272 independent reflections of which the number of reflections satisfying $I>2 \sigma(I)$ criteria were 6210. These were treated as observed. Corrections for Lorentz and Polarization effects were applied. It was confirmed that the crystal belongs to monoclinic crystal system and the space group is $C 2 / c$ (Figure 1). Compound 2: A total of 93968 reflections were collected, resulting in 7467 independent reflections of which the number of reflections satisfying $I>2 \sigma(I)$ criteria were 5951 . These were treated as observed. Corrections for Lorentz and Polarization effects were applied. It was confirmed that the crystal belongs to monoclinic crystal system and the space group is Pbca (Figure 2).

\section{Acknowledgement}

MNM thanks Principal and Management of M S Ramaiah Institute of Technology, Bangalore for their constant support and encouragement.

\section{References}

1. Anisimora VA, Levchenko MV, Kovalev GA, Spasov AA, Dudchenko GP, et al. (1987) Chem Abstr 108: 879b.

2. Goodgame DML, Machado AASC (1972) Inorg Chim Acta 6: 317.

3. Saksena RK, Srinivasa SK (1987) J Indian Chem Soc 64: 446.

4. Sluka J, Novak J, Budesinsky Z (1976) Coll Czech Chem Com 41: 3628.

5. Biradar NS, Davale S, Kulkarni VH (1973) Curr Sci 42: 125.

6. A Mishra, JP Singh, MP Singh (1978) J Indian Chem Soc 55: 23.

7. Kalmykov VV, Ivanov VA, Kharitonov GV (1979) Chem Abstr 52(4): 889.

8. Bruker Saintplus (1998) Program for data reduction. Bruker Axs Inc, Madison, Wisconcin, USA.

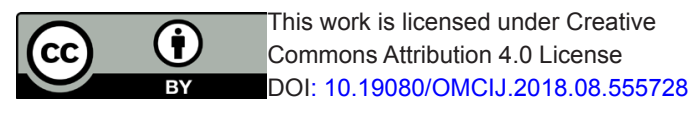

